\title{
MIDAS
}

Museus e estudos interdisciplinares

1 | 2013

Varia

\section{Las revistas museológicas en la actualidad: una panorámica global}

Museological journals today: a global survey

Jesús-Pedro Lorente

\section{OpenEdition}

Journals

Edición electrónica

URL: http://journals.openedition.org/midas/156

DOI: 10.4000/midas. 156

ISSN: 2182-9543

Editor.

Alice Semedo, Paulo Simões Rodrigues, Pedro Casaleiro, Raquel Henriques da Silva, Ana Carvalho

Referencia electrónica

Jesús-Pedro Lorente, «Las revistas museológicas en la actualidad: una panorámica global », MIDAS

[En línea], 1 | 2013, Puesto en línea el 29 abril 2013, consultado el 19 abril 2019. URL : http:// journals.openedition.org/midas/156; DOI : 10.4000/midas.156

Este documento fue generado automáticamente el 19 abril 2019.

\section{(c) (i) (2)(2)}

Midas is licensed under a Creative Commons Attribution-NonCommercial-ShareAlike 3.0 International License 


\section{Las revistas museológicas en la actualidad: una panorámica global}

Museological journals today: a global survey

Jesús-Pedro Lorente

\section{Principales publicaciones museológicas de centros de investigación}

1 Sin duda han desempeñado un papel fundamental en la consolidación de la museología como disciplina los centros de estudios que con carácter institucional. Fue el caso de la Oficina Internacional de Museos, dependiente de la Sociedad de Naciones, que en 1927 creó la revista Mouseion, en la que participaron reconocidos autores de todo el mundo que irían horadando gota a cota, un camino abierto a una nueva profesión con competencias propias, como metafóricamente explicó el crítico español Eugenio D’Ors en un artículo de 1828 titulado "Museografía" (recogido en Bolaños 2002, 78-79). Este precedente fue emulado por la UNESCO y su Museums Division, que crearon la más antigua publicación institucional especializada en el tema aún activa, y que ha servido de modelo a todas las demás, es la revista trimestral sobre museos dependiente de la UNESCO: en 1948 se empezó a publicar en inglés y francés con el nombre de Museum, y desde 1993 se llama Museum International, editándose también en árabe, chino y español ${ }^{1}$, además de las versiones en inglés y francés, que comercializa Blackwell Publishing.

2 A su vez, muchos países también crearon infinidad de revistas de novedades y ensayos sobre museos editadas por diferentes administraciones nacionales o locales; aunque entre las actualmente en activo sólo merece la pena citar aquí algunas que publican estudios y análisis con bibliografía, etc. Es el caso de veteranas revistas estatales como el Museumjournaal holandés, la danesa Museumsmagasinet, la polaca Muzealnictwo, la rusa МИР мУзЕЯ ("El mundo del museo", antes titulada "Museo Soviético"), o el Journal of Indian Museums. 
3 En España esta oferta llegó primero a través de las administraciones periféricas, como la Diputación Provincial de Barcelona, que publicó la Revista de Museus entre 1983 y 1987, o la Generalitat de Catalunya, que en 1988 empezó a publicar la revista De museus. Quaderns de museología y museografía, vigente más o menos hasta 1993 en que se pierde su pista en Dialnet, LatIndex $\mathrm{u}$ otras bases hemerográficas. Entre las revistas institucionales actuales la más veterana depende de la Junta de Andalucía que desde 2003 edita, con periodicidad más o menos semestral, Mus-A Revista de las instituciones del patrimonio histórico de Andalucía (sus números menos recientes se pueden descargar en http:// www.museosdeandalucia.es/cultura/museos/). Y en la administración central es el caso de la Subdirección General de Museos Estatales, que desde 2004 edita la elegante revista Museos.es con periodicidad más o menos anual, difundida en papel y también totalmente accesible por internet (http://www.mcu.es/museos/MC/MES/index.html).

Ha sido muy influyente este modelo español, donde se combinan la "propaganda" institucional con artículos de investigación museológica, pues a través de la red Ibermuseos $\mathrm{u}$ otros contactos ministeriales, ha servido de parangón para otras revistas similares en países afines al nuestro. Así en México, donde existía ya la prestigiosa Gaceta de Museos. Revista de la Coordinación Nacional de Exposiciones y Museos del INAH-CONACULTA, fundada en 1996, en lugar de afianzarla dándole periodicidad más regular, algún alto cargo decidió hacerle la competencia creando otra segunda revista, pero con papel couché y fotos a todo color, así que en 2004 nació M: Museos de México y del mundo, también editada por el CONACULTA e INAH, aunque ni sus contenidos ni su continuidad han sido mejores. Ese mismo año 2004 empezó también a publicarse Musas - Revista Brasileira de Museus e Museologia, lujosamente editada por el Departamento de Museus e Centros Culturais, Instituto do Patrimônio Histórico e Artístico Nacional (se pueden consultar los números antiguos agotados en http://www.museus.gov.br). Por su parte, la veterana Revista Museos , editada anualmente por la Subdirección Nacional de Museos de Chile, desde 2006 viviría una nueva época de mejoras con excelente diseño y fotos a color (algunos números también se pueden descargar en pdf desde el portal http://www.dibam.cl). Por último, por no hacer la lista demasiado larga, en esta categoría cabe destacar la portuguesa Museologia.pt, publicada por el Instituto dos Museus e da Conservação desde 2007 con periodicidad anual, en papel couché con ilustraciones en color. Otras muchas revistas institucionales sobre museos podrían citarse en nuestro entorno cultural, pero con carácter más divulgativo que analítico, de manera que apenas deberían considerarse revistas de museología, en el sentido estricto del término.

Una subcategoría aparte son las revistas dependientes de museos, que no dejan de ser publicaciones institucionales, y que pocas veces son publicaciones museológicas. El Boletín del Museo del Prado o La revue du Louvre son eminentemente revistas de historia del arte, y a su escala muchos otros museos publican revistas de su especialidad respectiva. Pero algunos museos sí editan revistas especializadas en museología, entre las cuales la publicación veterana y con gran prestigio en el sector es Curator: The Museum Journal, cuyo n. 1 fue publicado en enero de 1958 por el American Museum of Natural History de Washington -un centro de la Smithsonian Institution-, y luego pasó a depender de la California Academy of Sciences hasta 2010, pero desde el n. 53:1 la publica la editorial Wiley-Blackwell, con nuevo diseño y maquetación.

6 En España no hay nada similar, pues aunque museos tienen sus propias revistas, casi siempre están más relacionadas con el campo disciplinar de sus respectivas colecciones que con estudios de museología, por más que ocasionalmente recojan algún estudio sobre 
museos. En Portugal un caso a señalar, pues tiene una sección inicial titulada "Museus", con artículos sobre museos, no necesariamente arqueológicos, es la revista MUSA: museus, arqueologia e outros patrimónios, publicada desde 2004 por el Museu de Arqueologia e Etnografia do Distrito de Setúbal (MAEDS) y el Fórum Intermuseus do Distrito de Setúbal (FIDS). Pero el ejemplo más veterano en portugués sería Anais do Museu Paulista, cuyo origen se remonta a 1922 y que desde su refundación en 1993 lleva como título complementario História e Cultura Material, una apostilla que sitúa su campo de interés en la historia patrimonial en sentido lato, si bien tiene una sección fija específica sobre museos, y en las otras cinco a menudo también figuran artículos sobre estos temas.

7 No es casual, pues en la Universidad de São Paulo se ofertan estudios museológicos en distintos niveles y se creó un Instituto de Museologia, que en 1989 fundó la efímera Revista de Museologia. Por desgracia, por más que hoy en día hay tantos departamentos o centros de investigación universitarios especializados en estudios sobre museos, son escasos los que publican revistas propias. Los estudios sobre museos se ofertan hoy día en muchas universidades de todo el mundo, sobre todo en cursos de postgrado, tan numerosos que ya casi resulta imposible ofrecer un panorama completo, pues quedaría en seguida desfasado². Lo más habitual es que estén enfocados a la capacitación profesional; pero suelen culminar con la redacción de una tesis de maestría, que para muchos neófitos supone su primera (y última) contribución a la museología propiamente dicha. Bien pocas universidades publican esos trabajos, para beneficio de quienes quisieran hacer otros apoyándose en sus resultados, de manera que poco a poco fuésemos construyendo un corpus de conocimientos profesionales, a través de nuestros programas de postgrado y doctorados en museología.

8 Sigue siendo excepcional algún campus pionero como la Universidad de Brno, cuyo Departamento de Museología tiene una cátedra UNESCO de Museología y abundantes publicaciones, a las que ha añadido en 2012 la revista Museologica Brunensia. O el Departamento de Museología de la Universidad de Baroda, en la India, que desde 1965 publica la revista Studies in Museology. O el Department of Museum Studies de la Universidad de Leicester, que edita tantísimas publicaciones, incluyendo dos revistas científicas, pues desde 1994 mantiene en papel -y ahora también en pdf- la Museological Review dedicada a sus estudiantes de doctorado, y desde 2003 la prestigiosa revista digital cuatrimestral Museum and Society (http://www2.le.ac.uk/departments/museumstudies/ museumsociety); pero además difunde en su web muchas publicaciones digitales del Research Centre for Museums and Galleries (RCMG), creado en 1999 como un spin-off que realiza informes e investigaciones sociales por encargo. También ofertan estudios de museología a todos los niveles en el Institute of Archaeology del University College London, y desde 1996 publicitan sus investigaciones en el Journal of Conservation \& Museum Studies (consultable en http://www.ucl.ac.uk/ ycrnw3c/JCMS).

9 En el resto de Europa, una de las más veteranas es Reinwardt Studies in Museology, publicada anualmente por la holandesa Reinwardt Academie desde 1993. El mismo año nació también la acreditada Nordisk Museologi, publicada semestralmente, con contenidos en danés, noruego, sueco e inglés, por una red de institutos de investigación y departamentos universitarios de museología de los países nórdicos (los números antiguos se pueden consultar en http://www.nordiskmuseologi.org). Y también en 1993 se creó la portuguesa Cadernos de Sociomuseologia, una destacada revista científica editada por el Centro de Estudos de Sociomuseologia de la Universidade Lusófona de Lisboa: todos sus contenidos son accesibles on line ( http://revistas.ulusofona.pt/index.php/ 
cadernosociomuseologia), siendo básicamente trabajos académicos de los alumnos de su master y doctorado en Museología o de otros estudiosos, sobre todo militantes de una orientación sociológico-antropológica en línea con los legados museológicos del MINOM. Esta misma orientación prevalente tiene el doctorado internacional de museología de la Universidad de Avignon, que desde 2003 publica la excelente revista Culture \& Musées, dando continuidad a la titulada Publics et musées, fundada por Presses Universitaires de Lyon en 1992; aunque esta publicación semestral editada en papel y on line (http://www.univavignon.fr/fr/documentation/culture-et-musees/exemplaires-en-ligne.html) casi parece una lujosa iniciativa institucional, pues goza del apoyo financiero del Ministerio de Cultura y de la Region Provence-Alpes-Côte d'Azur. Más típicamente universitaria, en todos los sentidos, incluida cierta economía de medios, es la griega Museology. International Scientific Electronic Journal, publicación on line del Departamento de Tecnología Cultural y Comunicación en la Universidad del Egeo, que desde 2004 edita semestralmente artículos en griego e inglés, y de vez en cuando en otros idiomas. Por su parte, el Departamento de Museología de la Universidad de San Petersburgo edita desde 2010, en papel y on line, la revista вопросы мУзЕологии (Los problemas de la Museología), especializada en historia y teoría de la museología (http://history.spbu.ru/index.php?chpu=Voprosy_museologii).

En el continente americano hay también ejemplos de todo tipo. El más lujoso es de nuevo una revista francófona, la semestral Muséologies: Les cahiers d'études supérieures, publicada semestralmente desde 2006 por el programa de estudios superiores en museología de la Faculté des Arts, Université du Québec à Montréal para difundir, tanto en edición impresa como en versión digital gratuita (http://museologies.org), las investigaciones de los estudiantes de master y doctorado de las universidades del Quebec y de profesionales o investigadores en general. Más sobrias son sus equivalentes estadounidenses, como la que desde 2006 publica en pdf el Museum Studies Program de la Universidad de Oklahoma para dar a conocer las investigaciones de sus doctorandos, titulada CLS Journal of Museum Studies, que por ahora carece de ISSN y no tiene periodicidad fija.

Por lo que respecta a las universidades latinoamericanas, en lo relativo a los estudios museológicos la gran potencia es Brasil y, dejando de lado el ilustre precedente del Instituto de Museologia de la Universidad de de São Paulo, que en 1989 fundó la efímera Revista de Museologia, el epicentro actualmente está en Rio de Janeiro cuya Universidad Estatal imparte esta especialidad en todos los niveles, y difunde muy bien esas investigaciones. Primero fundó la publicación semestral Revista Eletrônica Jovem Museologia: Estudos sobre Museus, Museologia e Patrimônio, publicación digital (http:// www.unirio.br/jovemmuseologia) activa de 2006 hasta mediados de 2008, cuando le tomó el relevo la revista semestral Museologia e Patrimônio editada por el "Programa de PósGraduação em Museologia e Patrimônio" de la misma Universidad, incluyendo artículos en portugués y español, consultables gratis on line ( $\mathrm{http}: / /$ revistamuseologiaepatrimonio.mast.br). En cambio, México, que es otra potencia latinoamericana en estos estudios, no tiene revistas digitales de museología, ni siquiera la de más reciente aparición, la semestral Intervención: Revista Internacional de Conservación, Restauración y Museología, que creó en 2010 la Escuela Nacional de Conservación, Restauración y Museografía del INAH (en cuya web sólo se anuncian los contenidos del último número publicado (véase http://www.encrym.edu.mx).

12 En España no tenemos todavía en ningún campus ni cátedras, ni departamentos, ni centros de museología con esa especialidad declarada; ni tampoco hay ninguna instancia universitaria que publique una serie editorial específicamente dedicada a libros de 
museología o una revista con especialización museológica. Quizá la explicación esté en el hecho de que esa especialidad no está reconocida oficialmente como área científica autónoma, cosa que no deja de perjudicar la valoración científica en España de las revistas de museología institucionales o de asociaciones de museólogos, pues su evaluación e índices de calidad se miden en otras áreas de conocimiento como Bellas Artes, Biblioteconomía y Documentación, etc. ${ }^{3}$ Sin embargo, aunque reiteradamente y de forma injusta, quedan en la cola de nuestras publicaciones humanísticas, son revistas de buen nivel en su contexto disciplinar internacional, como en seguida veremos.

\section{Asociaciones y editoriales con publicaciones sobre museos}

Mucho antes de que lo hicieran las universidades y los poderes públicos, las asociaciones de profesionales de museos han sido pioneras en ofrecer cursos de formación, congresos y publicaciones especializadas. Nunca han dejado de hacerlo, y si en 1990 estas sociedades eran responsables de casi cincuenta revistas con tal especialización (según Gillette 1990, 195), hoy día hay muchas más. Pero no siempre es fácil distinguir entre meros boletines de noticias de actualidad e informaciones de interés, y las revistas que apuntan más alto, porque aspiran a ser vehículo científico de la investigación en museología, publicando artículos de estudio en profundidad, con cierta extensión, notas y bibliografía.

Lo habitual es que oferten en paralelo ambas cosas, como hace desde 1901 el Museums Journal publicado mensualmente por la británica Museum Association -la cual, además, analiza temas y casos de estudio considerados más por extenso en la publicación ocasional Museum Practice - $\mathrm{u}$ otras revistas de veteranas asociaciones nacionales, como la bimensual Museum News, órgano de expresión de la American Association of Museums desde 1924; Svenska Museer, publicada trimestralmente desde 1932 por la asociación sueca; Musées et Collections Publiques de France, editada trimestralmente desde 1955 por la asociación francesa de conservadores de museos públicos; o la venerable Museumskunde dependiente de la respectiva asociación alemana, en una nueva serie operativa desde 1960; así como Museum.ch, editada desde 1967 por la asociación suiza; Museumleben, editada por la asociación flamenca desde 1974; Museumvisie de la holandesa, desde 1976; Muse, que desde 1983 edita trimestralmente su equivalente canadiense; la de la irlandesa, Museum Ireland desde 1991; Neues Museum de la austríaca desde 1989, etc.

Esta apuesta combinada de divulgación y erudición, es también propia de la cuatrimestral Revista de Museología, editada desde 1994 por la Asociación Española de Museólogos, mientras que la revista anual Museo, publicada desde 1996 por la Asociación Profesional de Museólogos de España, suele tener carácter más monográfico, por recoger las ponencian presentadas en el congreso que cada año organiza esa sociedad sobre algún tema museístico. Por su parte, el Comité Español del ICOM, edita on line desde 2011 la revista ICOM-CE Digital con periodicidad irregular (consultable en http://www.icom-ce.org ) cuyos números suelen ser monográficos sobre determinados temas museísticos. Además, existen también algunas asociaciones territoriales, como la Associació de Museòlegs de Catalunya, constituida en 1995, que organiza congresos y publica la revista anual Mnemosine: Revista Catalana de Museología (pueden consultarse los índices y descargar algunos de sus artículos y dossiers en su portal http://www.museologia.cat). Por su parte, la Asociación de Museólogos y Museógrafos de Andalucía, fundada en 2009, también 
organiza cursos y otras actividades, sobre las que informa a través de las redes sociales y de su portal (http://www.asoc-amma.org).

Otra categoría más específica de asociaciones se interesan por un tipo concreto de museos, y por tanto sus publicaciones son también aún más especializadas. Es el caso de la italiana Nuova Museologia, que versa sobre ecomuseos y es el órgano de la Associazione Italiana di Studi Museologici (los índices de números aparecidos y algunos artículos son consultables en www.nuovamuseologia.org); mientras que en la revista Museologia Scientifica, se publican las actas de los congresos que promueve la Associazione Nazionale dei Musei Scientifici, Orti Botanici, Giardini Zoologici ed Acquari. En los Estados Unidos de América la asociación de educadores de museos Museum Education Roundtable, fundada en 1969, distribuye a sus miembros desde 1985 el Journal of Museum Education (algunos de sus artículos se pueden consultar libremente en http://museumeducation.info). La misma especialidad tienen las revistas británicas Journal of Education in Museums que con carácter anual publica desde 1981 el Group for Education in Museums, y Engage Journal, que desde 1996 reciben semestralmente los socios del foro Engage; mientras que el Geological Curators' Group publica desde 1974 la revista semestral Geological Curator, el Biological Curators Group edita desde 1989 el Journal of Biological Curation, el Museum Ethnographers Group envía a sus miembros desde 1989 la revista anual Journal of Museum Ethnography y la Natural Sciences Collections Association publica The Biology Curator desde 1994. En España lo más parecido a este tipo de asociaciones especializadas sería quizá la Asociación de Museólogos de la Iglesia en España, fundada en 1988, que periódicamente organiza reuniones, de cuyo programa y conclusiones informa en su web (http://www.museosdelaiglesia.es/ actividades.htm).

17 Por último, cabe señalar, también en este caso, el creciente protagonismo de las editoriales e iniciativas privadas. Si esta simbiosis ya se ha señalado como frecuente para las publicaciones de instituciones, es tanto más habitual que las asociaciones de museólogos dejen la gestión de sus publicaciones en manos de potentes grupos editoriales: así, la revista Musei e Gallerie d'Italia, dependiente de la Associazione Nazionale dei Musei Italiani, es publicada semestralmente por la editorial romana De Luca; de la bianual Visitor Studies, creada por la estadounidense Visitor Studies Association se encarga Routledge; y Museum Anthropology, que es el órgano de expresión de la American Anthropological Association-Council for Museum Anthropology, es publicada por la editorial Wiley-Blackwell.

18 Además, por supuesto, hay editoriales que tienen prestigiosas publicaciones museológicas, y es de suponer que serán rentables, lo cual podría servir como prueba definitiva de la consagración social de esta disciplina en la actualidad. En inglés es líder en el sector la citada Routledge, que publica trimestralmente la revista museológica de mayor impacto, The International Journal of Museum Management and Curatorship (MMC), y varias series de libros dedicadas a estudios sobre museos, entre los que se incluyen manuales y compilaciones (como Corsane 2005); pero le siguen de cerca Ashgate Press, que también tiene en su catálogo muchos libros de museos, incluyendo algunas antologías (como la editada por Preziosi y Farago 2004), o la ya mencionada editorial Wiley-Blackwell (que publicó la recopilación museológica a cargo de Macdonald 2006), u otras más pequeñas como Left Coast Press, de la cual dependen las revistas semestrales como Museums \& Social Issues o Museum History Journal y Common Ground Publishing, responsable de The International Journal of the Inclusive Museum. 

Akal, Ariel, pero con diferencia la que más se ha volcado en estos estudios es la asturiana Trea, que también publica desde 2009 la revista trimestral Hermus (algunos de sus artículos son consultables gratis en http://revistahermus.blogspot.com). En francés la editorial franco-canadiense L'Harmattan es la que más colecciones y títulos de museología tiene en catálogo, seguida de Armand Colin, y otras muchas. En alemán destaca la muniquesa Verlag CMS, que publica abundantes libros de museología y además la revista Museum Aktuell, con gran difusión en su versión on line, que es de pago (http:// www.museum-aktuell.de); aunque en este medio cuentan con un competidor tan fuerte como Virtual Library Museen, responsable de uno de los más activos foros digitales sobre museos que es H-Net Museum, y también de la revista Museologie Online (http://www.vlmuseen.de/m-online/redaktion.htm). En griego la editorial ateniense Kaleidoskopio publica anualmente desde 2004 Tetradia Mouseiologias. En ruso la publicación líder no está a la venta, es la revista mensual музЕЙ (Museo), que se adquiere únicamente por subscripción (http://panor.ru/journals/museum/archive/). Y en formato digital acaba de nacer en 2013 la revista semestral MIDAS - Museums and Interdisciplinary Studies, editada por un panel de museólogos portugueses en el portal francés OpenEdition, que publica en libre acceso artículos en inglés, francés, portugués y español. Es de esperar que en el futuro publiquen las ponencias y comunicaciones presentadas a las convocatorias del Seminario de Investigación Iberoamericano de Museología (SIAM) que hasta ahora han ido celebrándose en Oporto (2009), Buenos Aires (2010), Madrid (2011) y Rio de Janeiro (2012). Ojalá estos foros museológicos se consoliden, y surjan muchos más.

\section{BIBLIOGRAFÍA}

Aquilina, Janick Daniel. 2011. "The Babelian tale of museology and museography. A history of words". Museology. International Scientific Electronic Journal. 6. Consultable en: http:// museology.ct.aegean.gr

Araujo, Marcelo Mattos y Maria Cristina Oliveira Bruno, orgs. 1995. A memória do pensamento museológico contemporâneo. Documentos e depoimentos. São Paulo: Comité Brasileiro do ICOM.

Baur, Joachim, ed. 2010. Museumsanalyse. Methoden und Konturen eines neuen Forschungsfeldes. Bielefeld: Transcript.

Bellaigue, Matilde. 2000. “22 ans de réflexion muséologique à travers le monde”. Cahiers d'études/ Study Series ICOFOM 8:4-5.

Bolaños, María, ed. 1997. La memoria del mundo. Cien años de museología, 1900-2000. Gijón: Trea.

Cândido, Manuelina Maria Duarte. 2003. “Ondas do pensamento museológico brasileiro”. Cadernos de Sociomuseologia 20(20):51-162.

Corsane, Gerard, ed. 2005. Heritage, museums and galleries. An introductory reader. Londres y Nueva York: Routledge.

MIDAS, 1 | 2013 
Dolák, Jan, ed. 2009. Museology at the beginning of the $3^{\text {rd }}$ millennium. Brno: Technické Muzeum v Brne: 75-96.

Edson, Gary. 1995. International directory of museum training. Londres y Nueva York: Routledge.

Gillette, Arthur. 1990. “La bonne parole: Les revues muséales”. Museum XLII (4): 194-225.

Hernández Hernández, Francisca. 2006. Planteamientos teóricos de la museología. Gijón: Trea.

Lorente, Jesús Pedro. 2010. “Los estudios de museología en las universidades españolas”. Revista de Museología 47:72-80 (dossier sobre la formación universitaria en museología en países de habla hispana).

Lorente, Jesús Pedro. 2012. "The development of museum studies in universities: from technical training to critical museology". Museum Management and Curatorship.

Macdonald, Sharon, ed. 2006. A companion to museum studies. Malden, Mass.; Oxford: Blackwell Pub.

Malt, Carol. 1987. "Museology and museum studies programs in the United States: part one". International Journal of Museum Management and Curatorship 6:165-172.

Maroevic, Ivo y Edson, Gary. 1998. Introduction to museology: the European approach. Munich: C. Müller-Straten.

McClellan, Andrew. 2007. “Museum studies now”. Art History 30(4):566-570.

Mensch, Peter van, et al. 1989. Professionalising the muses: the museum profession in motion. Amsterdam: AHA Books.

Preziosi, Donald y Claire Farago, ed. 2004. Grasping the world. The idea of the museum. Aldershot y Burlington: Ashgate Press.

Scheiner, Tereza Cristina. 2008. "El mundo en las manos: museos y museología en la sociedad globalizada”. Cuicuilco: Revista de la Escuela Nacional de Antropología e Historia 15(44):16-36.

Viereg, Hildegard K., Mónica Risnicoff de Gorgas, Regina Schiller y Martha Troncoso, eds. 2006. Museology - A field of knowledge. Museology and history/museología: Un campo del conocimiento. Museología e historia (ICOFOM Study Series 35). Munich: Museo Nacional Estancia Jesuítica de Alta Gracia y Casa del Virrey Liniers.

Woodhead, Peter y Geoffrey Stansfield. 1994. Keyguide to information sources in museum studies. 2. ed. Londres: Mansell.

\section{NOTAS}

1. La versión española ya sólo se publica on line y con retraso (http://portal.unesco.org/culture/ es/ev.php-URL_ID=2356\&URL_DO=DO_TOPIC\&URL_SECTION=201.html).

2. Cuando en 1968 se creó dentro del ICOM el Comité Internacional para la Formación del Personal (ICTOP), una de sus primeras tareas fue publicar un World Directory of Museology Courses y hasta 2007 había un largo listado internacional de cursos en la web oficial del ICTOP, pero lleva años retirado y está resultando muy laborioso actualizarlo, aunque se han comprometido a hacerlo. Entre tanto, han dejado de actualizarse los directorios que en los años noventa todavía publicaban editoriales como Mansell o Routledge (Woodhead \& Stansfield 1994; Edson, 1995 muy completos sobre todo en lo concerniente a Estados Unidos de América, Canadá, Reino Unido o Australia). ¡Ya no se reeditan, ni siquiera en formato digital! Para lo concerniente a los estudios 
superiores de museología en países de habla hispana, remito al dossier de artículos que yo mismo he coordinado en el no 47 de la Revista de Museología (Lorente 2010).

3. Sobre el sistema de Valoración Integrada de Revistas Españolas de Ciencias Sociales y Humanas (RESH), su funcionamiento y categorías véase http://epuc.cchs.csic.es/resh/indicadores? at=BELLAS\%20ARTES

\section{RESÚMENES}

El nacimiento de la revista MIDAS añade un nuevo título a la lista creciente de publicaciones periódicas especializadas en museos y museología. Ello plantea una buena ocasión para reflexionar sobre la oferta global de esas revistas, cuya contribución a la consolidación de la Museología como disciplina hay que reconocer. Ese es el argumento de este artículo, basado en el capítulo final de un Manual de Historia de la Museología, publicado por Editorial Trea en 2012.

The birth of the MIDAS journal adds a new title to the expanding list of periodicals specialising in museums and museology. It is a good occasion for reflecting on the global offer of such journals, whose contribution to the validation of Museology as a discipline must be acknowledged. This is the point of this article, based on the last chapter of a handbook Manual de Historia de la Museología , published by Editorial Trea in 2012.

\section{ÍNDICE}

Keywords: museology, universities, museum, associations, publishers

Palabras claves: museología, universidades, museos, asociaciones, editoriales

\section{AUTOR}

\section{JESÚS-PEDRO LORENTE}

Profesor titular en el Departamento de Historia del Arte de la Universidad de Zaragoza. En esta universidad imparte, entre otras, la asignatura optativa de "Museología", que él mismo activó por primera vez en 1997, y la de "Museología crítica" en el Master en Museos: Educación y Comunicación del cual es coordinador de contenidos académicos. Es también coordinador del grupo de investigación Observatorio Aragonés de Arte en la Esfera Pública e investigador principal del proyecto I+D Arte público para todos: propuestas de estudio y musealización virtual (desde enero de 2010). Entre sus publicaciones cabe destacar el libro Los museos de arte contemporáneo: noción y desarrollo histórico (Trea) de 2008 (editado en francés por L'Harmattan en 2009 y en inglés por Ashgate en 2011), y la dirección editorial del libro Museología crítica y arte contemporáneo (Prensas Universitarias de Zaragoza) de 2003.jpl@unizar.es 